\title{
Delay of reinforcement and delay shifts in dyadic communication
}

\author{
ROBERT FRANK WEISS, MICHELE K. STEIGLEDER, and ROBERT E. CRAMER \\ University of Oklahoma, Norman, Oklahoma 73019
}

and

\author{
RICHARD A. FEINBERG \\ Ohio State University, Lima, Ohio 45804
}

\begin{abstract}
Participation in dyadic communication can be reinforced by the opportunity to speak in reply. Social analogs of delay of reinforcement and shifts in delay of reinforcement were investigated. In an experimental conversation modeled on discrete-trials instrumental conditioning, instrumental response speeds were faster when the opportunity to speak in reply was immediate rather than delayed $(p<.005)$. Subjects shifted from short- to long-delay matched speeds with constant long-delay controls, while subjects shifted from long- to short-delay matched speeds with constant short-delay controls $(\mathrm{N}=128)$.
\end{abstract}

A continuing series of experiments in dyadic communication shows a pattern of results which bears a striking functional similarity to discrete-trials instrumental escape conditioning. Experimental demonstration of our theoretical analogies extends well beyond the analogs of acquisition and extinction, commonly deemed sufficient in social psychology or behavior therapy, to include analogs of partial reinforcement effects, intermittent shock effects, delay of reinforcement effects, drive effects, correlated reinforcement effects (discrete-trials DRL), and correlated delay of reinforcement effects (e.g., Weiss, Boyer, Colwick, \& Moran, 1971; Weiss, Lombardo, Warren, \& Kelley, 1971). Our principal aim in these experiments has been to illuminate interesting problems in social psychology and to advance general behavior theory through the extension of learning principles to social behavior. Given the extent of the analogy revealed in our laboratory, it seems intriguing, if hardly prudent, to explore the possibilities of using our dyadic communication situation to directly address problems in behavior theory for which no definitive data from simple animal conditioning experiments yet exist. We are encouraged in this enterprise by the successful investigation of a drive theory of learned helplessness (Feinberg, Weiss, Miller, Steigleder, \& Lombardo, Note 1). The purposes of the present study are both more modest in scope and less propitious methodologically. Recent advances in the neo-Hullian theory of instrumental conditioning (Capaldi, in press; McHose \& Moore, 1976) call for data on the effects of shifts in delay of reinforcement. We now report such a study employing a social analog of instrumental conditioning.

Reprints should be requested from R. F. Weiss, Department of Psychology, University of Oklahoma, Norman, Oklahoma 73019.

\section{METHOD}

On each trial, the subject listened to another person's viewpoint and could then press a switch (the instrumental response), the reinforcement for which was the opportunity to speak in reply to the other person.

\section{Design}

In order to assess the effects of delay of reinforcement and shifts in delay of reinforcement, we employed a straightforward and familiar four-group design in which one group begins training under short delay and is then shifted to long, a second group begins training under long delay and is then shifted to short, together with two unshifted constant delay groups, constant short and constant long. Prior to the shift, of course, there are only two experimental treatments, short vs. long delay, and these treatments may be compared to assess delay effects prior to the shift. The effects of shifts in delay of reinforcement (including possible contrast effects) can be assessed by comparing the performance of the shifted groups with the performance of the two constant groups. Traditionally, a well-controlled experiment should bring performance to an asymptote before shifting. Recent developments in neo-Hullian theory (Capaldi, in press; McHose \& Moore, 1976) maintain the interest in "asymptotic" performance but also address the question of comparison of preasymptotic with asymptotic shifts. Other recent developments make repeated shifts in reinforcement conditions a question of lively interest (compare Gracely \& Church, 1976; Logan, 1968; McCain, Lobb, Almand, \& Leck, 1976). Our dyadic communication analog of escape conditioning requires the simple design employed here because the subjects' inability to maintain sustained conversations limits the number of trials available for experimental comparison or, indeed, to guarantee asymptotic preshift performance within a set of massed trials.

\section{Deception and Masking Task}

The experiment was represented to the subjects as a study of opinion change. "We are interested in how your opinion may be affected by what someone else says, how your opinion may be affected by what you yourself say, and how what you say may affect the opinions of someone else." As a masking task, after each statement and reply, the subject indicated whether he had changed his opinion by moving a dial. Questionnaire data showed that the subjects believed this deception; the switch 
appeared to them as a mere incidental to the serious business of opinion change through conversation. The "other person," simulated by a tape recorder, was said to be in another room from the subject, and the experimenter was in fact in another room. The subject addressed the "other person" and the experimenter over an intercom system and could also hear the experimenter give instructions and occasional comments ("Speak a little louder, Subject A") to the nonexistent other person.

\section{Apparatus and Procedure}

The subject was seated at a table facing the control room wall, which included four one-way vision windows. Instructional signals appeared in each window upon illumination. The signals were the large printed words (1) "listen," (2) "throw switch if you wish to comment," (3) "talk," and (4) "move dial to final opinion." A panel mounted on the table top contained the subject's "comment" switch (a telephone toggle switch with a spring return), his intercom, and the masking-task opinionchange dial.

An experimental trial began with the "listen" signal and the playing of the taped topic and opinion by the other person. When the taped message ended, the experimenter operated the control which simultaneously (a) presented the CS, the signal "throw switch if you wish to comment," and (b) started the latency timer. When the subject threw the comment switch, the latency timer automatically stopped, measuring latency to .01 sec. The "talk" signal followed the switch-press response after a delay automatically regulated by an interval timer and the subject spoke in reply. The procedure described was closely modeled on traditional discrete-trials instrumental conditioning. The reinforcement (speaking in reply) was contingent on the instrumental response (switch pressing). The dependent variable was speed (100/latency), measured from the time of the presentation of the CS (signal "press switch if you wish to comment") to the instrumental switch-pressing response.

Short and long delay, automatically regulated by the interval timer, were 0 and $12 \mathrm{sec}$, respectively. Selection of these delay intervals was intended to produce delay differences by the switch point, with a long delay, of course, capable of sustaining acquisition, and was based on our previous experiments which included a perfectly monotonic six-point delay gradient $(0$, $3,6,9,15$, and $21 \mathrm{sec}$ ) in which all six delays did sustain acquisi- tion. For further details of the delay procedure, see Weiss, Boyer, Colwick, and Moran, (1971).

\section{Subjects and Materials}

The subjects were 128 undergraduates from the introductory psychology pool, 32 in each of the four conditions. The experiment was counterbalanced for sex, even though previous research indicated no main or interactive effects of sex (with the present experiment confirming this).

The opinions expressed by the "other person" were selected by means of a questionnaire administered to 100 subjects from the introductory psychology pool. Selection criteria were that the opinions should be reasonably consistent with each other and dissimilar from the opinions of the introductory psychology students. The "other person" cassette tapes were the same sex as the subject, had a moderate regional accent characteristic of in-state students, were carefully gauged to approximate the articulateness and sophistication of a typical subject, and were presented in four randomized orders counterbalanced with each experimental condition.

\section{RESULTS AND DISCUSSION}

Figure 1 shows an apparent pattern in which acquisition continues throughout training; short delay is faster than long delay, with the difference becoming gradually clearer as the curves diverge over trials; subjects shifted to short match speeds with the constant short; subjects shifted to long match speeds with the constant long; and there was no sign of contrast effects. The acquisition effects begun before the shift $(p<.001)$ continued to be statistically significant after the shift $[F(5,600)=$ $3.04, p=.01]$. The delay effect reached conventional levels of statistical reliability only after the shift. Analysis confirmed that short delay was faster than long delay over a block of the last four trials $[\mathrm{t}(126)=3.17$, $\mathrm{p}<.005$ ] following Tukey tests which confirmed the
Figure 1. Delay of reinforcement: Acquisition curves of mean response speed under constant and shifted delay of the opportunity to speak in reply.

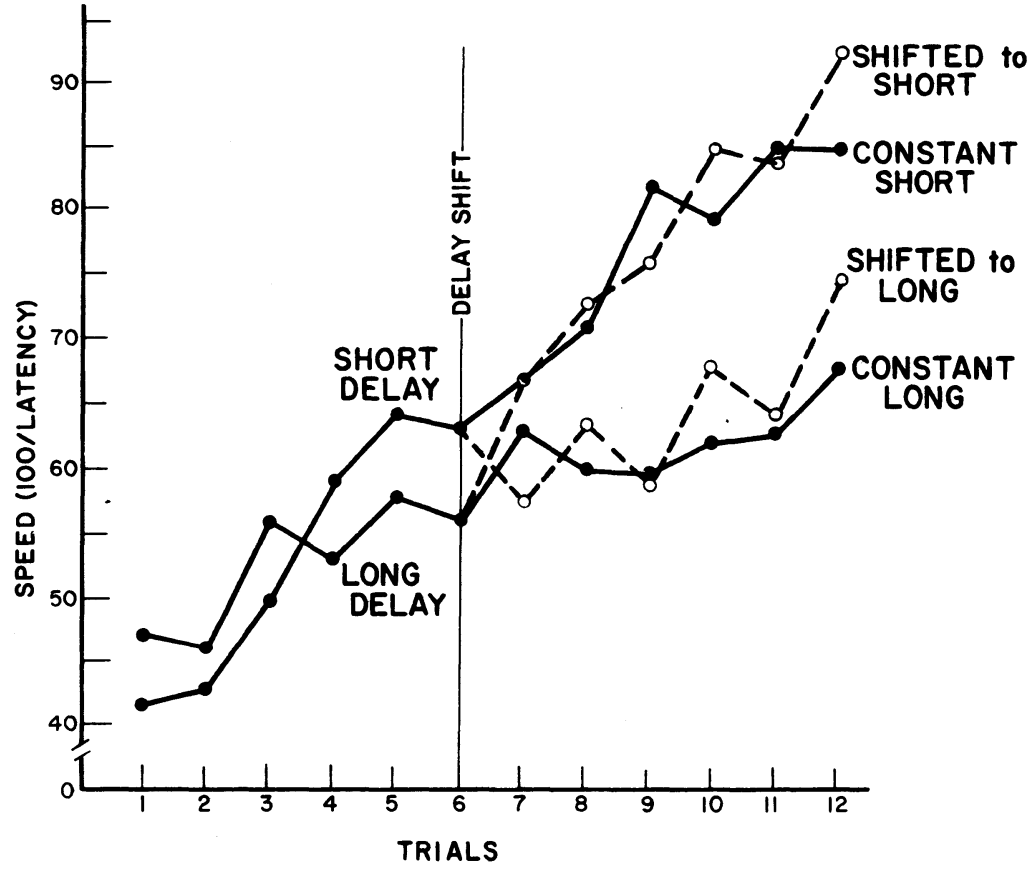


matching of the speeds of the shifted groups to those of the constant delay groups.

The acquisition effects, the gradual divergence of short and long delay over trials, and the significant delay effect all support our instrumental escape conditioning model of dyadic communication, not least in the replicability of experimental results, itself something of a novelty in social psychology.

In exploring the possibilities of using our dyadic communication situation to directly address problems in behavior theory for which no definitive data from animal conditioning experiments yet exist, we have at least two possible sources of inference at hand. One such source of inference is neo-Hullian theory, interesting new developments in which are, however, most directly addressed to instrumental reward conditioning rather than to instrumental escape conditioning (Capaldi, in press; McHose \& Moore, 1976). Turning more directly to escape conditioning, a second source of inference may be found in reinforcement magnitude shift effects in escape conditioning, upon the not unfamiliar assumption that magnitude and delay of reinforcement function similarly. Both sources of inference imply that groups shifted to a shorter or longer delay can match speeds with a group constantly maintained at the shifted groups new level of delay, as found in the present study. Both sources of inference can be used to address the question of the particular circumstances in which contrast effects (not found in this study) may or may not emerge. The theories of Capaldi (in press) and of McHose and Moore (1976). predict that the occurrence and detectability of contrast effects are dependent upon the number of preshift trials. Thus, for example, "the extent of negative contrast should be a monotonically increasing function of the amount of pre-shift training" (McHose \& Moore, 1976, p. 300) or, as Capaldi writes in the portion of his paper devoted to positive contrast (Capaldi, in press, preprint pp. 18$20)$, "the delay interval functions as does any other reward reduction. .. The greater the number of pre-shift trials the faster will be running in post-shift... A larger PCE presumably implies a more reliable PCE..." Our data do not contradict the predictions of Capaldi and McHose and Moore with regard to contrast effects insofar as these theories may be applicable to escape conditioning. In turning to escape conditioning research as a source of inference, it will be essential to be closely attentive to the terminological inconsistencies which bedevil the area because studies which are entirely or primarily concerned with drive shifts show clear-cut positive and negative drive contrast effects (Nation, Wrather, \& Mellgren, 1974, see p 72; Woods \& Schutz, 1965), while studies of the effects of shift in the magnitude of reinforcement (incentive contrast) report either no contrast effects whatsoever (Bower, Fowler, \& Trapold, 1959; Howe, 1961) or negative contrast (Woods, 1967). Bridging the inferential gap between studies of magnitude of reinforcement in animal escape conditioning and the present dyadic communication delay research are our studies of reinforcement magnitude shifts in dyadic communication which found negative contrast (Lombardo, Tator, \& Weiss, 1972) and no contrast (Denton \& Weiss, Note 2). The delay shift results of the present study are thus, entirely consistent with inferences based on magnitude of reinforcement effects in escape conditioning and in analogs of escape conditioning which are closely related to the present communication study.

This experiment confirms an instrumental escape conditioning model of dyadic communication based on known characteristics of escape conditioning and adds to our knowledge of those characteristics.

\section{REFERENCE NOTES}

1. Feinberg, R. A., Weiss, R. F., Miller, F. G., Steigleder, M. K., \& Lombardo, J. P. Drive as a unifying concept in learned helplessness: Theory and experiments. Mimeographed manuscript, University of Oklahoma, 1976.

2. Denton, D. A., \& Weiss, R. F. Drive and reinforcement analogs in conversation. Unpublished manuscript, University of Oklahoma, 1976.

\section{REFERENCES}

Bower, G. H., Fowler, H., \& Trapold, M. A. Escape learning as a function of amount of shock reduction. Journal of Experimental Psychology, 1959, 58, 482-484.

CAPALDI, E. J. Reinforcement level: An expectancy-associative approach to relative reinforcement and nonreinforcement effects. In J. W. Baerwaldt (Ed.), Arlington symposium on learning. Stamford, Conn: Greylock, in press.

Gracely, R. H., \& Church, R. M. Adjustment of speed in repeated shifts of a negative reinforcer. Bulletin of the Psychonomic Society, 1976, 7, 455-457.

HowE, E. S. The effect of an increased versus a decreased reduction in shock used as incentive. American Journal of Psychology, 1961, 74, 462-466.

LoGAN, F. A. Incentive theory and changes in reward. In K. W. Spence \& J. T. Spence (Eds.), The psychology of learning and motivation (Vol. 2). New York: Academic Press, 1968. Pp. 1-30.

Lombardo, J. P., Tator, G. D., \& Weiss, R. F. Performance changes in human conditioning as a function of shifts in the magnitude of attitudinal reinforcement. Psychonomic Science, 1972, 28, 215-218.

McCain, G., Lobb, M., Almand, W., \& Leck, D. Delay of reinforcement: Extended training and multiple shifts. Bulletin of the Psychonomic Society, 1976, 7, 539-541.

McHose, J. H., \& Moore, J. N. Expectancy, salience, and habit: A noncontextual interpretation of the effects of changes in the conditions of reinforcement on simple instrumental responses. Psychological Review, 1976, 83, 292-307.

Nation, J. R., Wrather, D. M., \& Mellgren, R. L. Contrast effects in escape conditioning of rats. Journal of Comparative and Physiological Psychology, 1974, 86. 69.73.

Weiss, R. F., Boyer, J. L., Colwick, J. T., \& Moran, D. J. A delay of reinforcement gradient and correlated reinforcement in the instrumental conditioning of conversational behavior. Journal of Experimental Psychology, 1971, 90, 33-38.

Weiss, R. F., Lombardo, J. P., Warren, D. R., \& Kelley, K. A. The reinforcing effects of speaking in reply. Journal of Personality and Social Psychology, 1971, 20, 186-199. 
Woods, P. J. Performance changes in escape conditioning following shifts in the magnitude of reinforcement. Journal of Experimental Psychology, 1967, 75, 487-491.

Woods, P. J., \& SchUtz, L. J. Performance in instrumentalescape conditioning following a shift in drive-stimulus intensity. Proceedings of the 73rd Annual Convention of the American Psychological Association, 1965, 23-24.

(Received for publication October 13, 1976.) 